\title{
Physical properties of High Arctic tropospheric particles during winter
}

\author{
L. Bourdages ${ }^{1}$, T. J. Duck ${ }^{1}$, G. Lesins ${ }^{1}$, J. R. Drummond ${ }^{1}$, and E. W. Eloranta ${ }^{2}$ \\ ${ }^{1}$ Department of Physics and Atmospheric Science, Dalhousie University, Halifax, Canada \\ ${ }^{2}$ Space Science and Engineering Center, University of Wisconsin, Madison, USA
}

Received: 11 March 2009 - Published in Atmos. Chem. Phys. Discuss.: 24 March 2009

Revised: 4 August 2009 - Accepted: 5 August 200 - Published: 21 September 2009

\begin{abstract}
A climatology of particle scattering properties in the wintertime High Arctic troposphere, including vertical distributions and effective radii, is presented. The measurements were obtained using a lidar and cloud radar located at Eureka, Nunavut Territory $\left(80^{\circ} \mathrm{N}, 86^{\circ} \mathrm{W}\right)$. Four different particle groupings are considered: boundary-layer ice crystals, ice clouds, mixed-phase clouds, and aerosols. Twodimensional histograms of occurrence probabilities against depolarization, radar/lidar colour ratio and height are given. Colour ratios are related to particle minimum dimensions (i.e., widths rather than lengths) using a Mie scattering model. Ice cloud crystals have effective radii spanning 25$220 \mu \mathrm{m}$, with larger particles observed at lower altitudes. Topographic blowing snow residuals in the boundary layer have the smallest crystals at $15-70 \mu \mathrm{m}$. Mixed-phase clouds have water droplets and ice crystal precipitation in the $5-40 \mu \mathrm{m}$ and $40-220 \mu \mathrm{m}$ ranges, respectively. Ice cloud crystals have depolarization decreasing with height. The depolarization trend is associated with the large ice crystal sub-population. Small crystals depolarize more than large ones in ice clouds at a given altitude, and show constant modal depolarization with height. Ice clouds in the mid-troposphere are sometimes observed to precipitate to the ground. Water clouds are constrained to the lower troposphere $(0.5-3.5 \mathrm{~km}$ altitude). Aerosols are most abundant near the ground and are frequently mixed with the other particle types. The data are used to construct a classification chart for particle scattering in wintertime Arctic conditions.
\end{abstract}

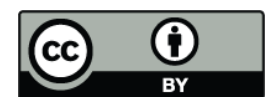

Correspondence to: T. J. Duck

(tom.duck@dal.ca)

\section{Introduction}

The climate of the Arctic troposphere is known to be sensitive to change (Serreze et al., 2009), but a detailed understanding of infrared radiative transfer central to the problem remains limited by the availability of suitable measurements. Experimental progress has historically been impeded by accessibility barriers to the remote North and the harsh environmental conditions. This is particularly true for the High Arctic during winter, when $24 \mathrm{~h}$ darkness leads to mean surface temperatures in the vicinity of $-40^{\circ} \mathrm{C}$ (Lesins et al., 2009b). Passive satellite sensors also encounter difficulties owing to the unique radiative character of the polar regions (Curry et al., 1996), and so the environmental impediments must be overcome if all of the observational gaps are to be filled.

An experimental effort to provide comprehensive yearround measurements in the High Arctic has been undertaken by the Canadian Network for the Detection of Atmospheric Change (CANDAC), who established the Polar Environment Atmospheric Research Laboratory (PEARL) at Eureka, Nunavut Territory $\left(80^{\circ} \mathrm{N}, 86^{\circ} \mathrm{W}\right)$ in collaboration with Environment Canada (EC). The site is co-located with the Eureka Weather Station on the coast of Ellesmere Island (Fig. 1), and is the most northern permanent civilian research facility in Canada. A suite of remote-sensing and insitu instruments was installed by CANDAC and the National Oceanic and Atmospheric Association (NOAA) Study of Environmental Arctic Change (SEARCH) programme. Measurements are being collected on an ongoing basis, and span from the surface to $100 \mathrm{~km}$ in altitude. Several different instruments can characterize tropospheric particles, which are known to play a key role in the Arctic radiative exchange (Curry et al., 1993).

We present a climatology of tropospheric particle scattering properties obtained with a lidar and cloud radar at

Published by Copernicus Publications on behalf of the European Geosciences Union. 


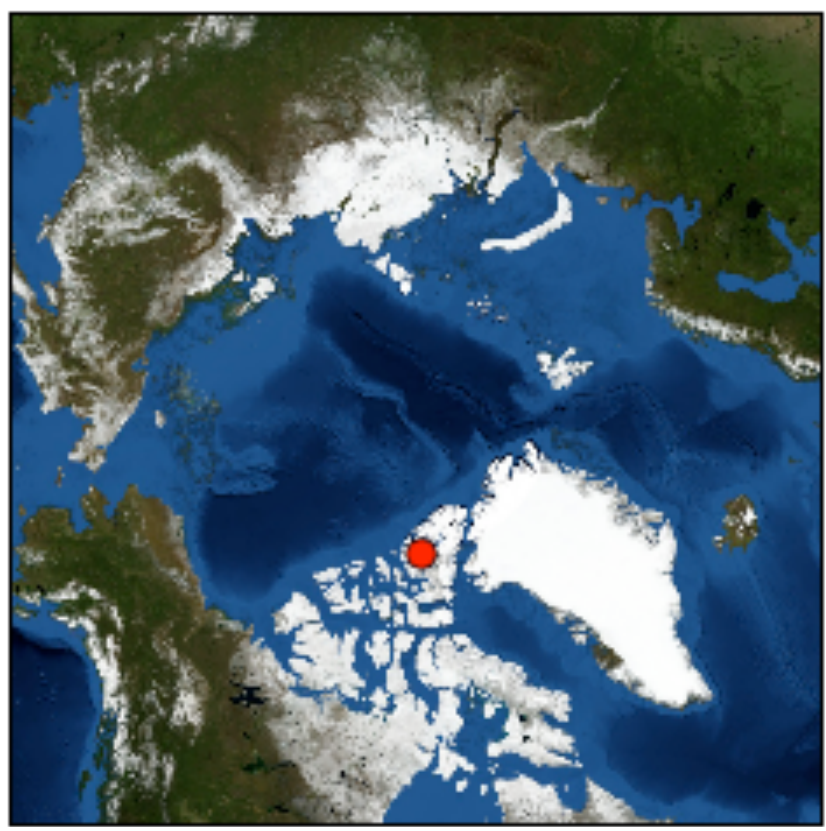

Fig. 1. Polar map of the Arctic. The location of Eureka $\left(80^{\circ} \mathrm{N}\right.$, $86^{\circ} \mathrm{W}$ ) is marked with a red dot.

PEARL during the three complete and consecutive winters between 2005 and 2008. March is included as a wintertime month because it is similar climatologically to December through February at Eureka (Lesins et al., 2009a). The lidar and radar are operated continuously, and the data coverage is reasonably uniform across the period of interest.

The measurements provide information on particle vertical distributions and sizes that was previously lacking for the winter months. Four different categories of particles are considered: boundary-layer ice crystals, ice clouds, mixed-phase clouds, and aerosols. Each of these can be expected to impact radiative transfer and wintertime climate.

Early studies proposed a role in the radiative exchange for "diamond dust" ice crystals that nucleate in the very cold conditions found at high latitudes during winter (e.g., Curry, 1983), but subsequent measurements indicated they have a negligible impact (Intrieri and Shupe, 2004). Ice precipitation from thin water clouds can be mistaken for diamond dust (Intrieri and Shupe, 2004), as can residual blowing snow lofted from mountainous terrain (Lesins et al., 2009a). Clouds in general play a major role in the radiative transfer (Curry et al., 1996). Aerosols, on the other hand, have a small impact on scattering and visibility (Hoff, 1988; Trivett et al., 1988; Leaitch et al., 1989), but may promote dehydration and so play a key role in the radiative exchange nonetheless (Blanchet and Girard, 1995).

Several Arctic campaigns have been conducted to measure particle optical, macro- and microphysical characteristics: the Canadian Arctic Haze Study and Arctic Gas and Air
Sampling Program (AGASP; see Leaitch et al., 1989 and references therein), the FIRE Arctic Clouds Experiment (FIREACE; Curry et al., 2000), the Surface Heat Budget of the Arctic Ocean campaign (SHEBA; Uttal et al., 2002), and the Mixed-Phase Arctic Cloud Experiment (MPACE; Verlinde et al., 2007). Such activities are most often conducted during the spring and summer and are typically of short duration, rarely longer than a few months to a year. Multi-year statistical data sets are needed, particularly for particle sizes, shapes and phases, which are directly related to radiative properties (Curry et al., 2000). Of the aircraft campaigns listed above, not one was conducted during the winter months. The SHEBA experiment stands out from previous studies in that it collected a year of data from a ship frozen into the Arctic Ocean. Year-round remote sensing measurements from the North Slope of Alaska - Adjacent Arctic Ocean (NSA-AAO) site near Barrow, Alaska $\left(71.3^{\circ} \mathrm{N}, 156.6^{\circ} \mathrm{W}\right)$ have also been used to investigate particles (Zhao and Garrett, 2008). The PEARL experiment was designed to build upon these earlier activities, and provides an opportunity to obtain comprehensive long-term data sets in the High Arctic.

This paper is structured as follows. Section 2 describes the active remote sensors used: a High Spectral Resolution Lidar and a Millimeter-wave Cloud Radar. Section 3 explains the categorization process and describes the lidar-radar colour ratio and its conversion to particle effective radius using Mie theory. Results are presented in Sect. 4, and then discussed in Sect. 5. Distributions of particle sizes, altitude ranges, and depolarization values are reviewed and compared with other measurements. Of particular interest will be Table 4, which summarizes the observed scattering properties of ice, water and aerosol particles, and their vertical distributions. Section 6 reviews the results and discusses future research possibilities.

\section{Instrumentation}

\subsection{The Zero-altitude PEARL Auxiliary Laboratory}

The measurements were obtained at the Zero-altitude PEARL Axillary Laboratory (ØPAL), which is co-located with the Eureka Weather Station at $10 \mathrm{~m}$ elevation above sea level. ØPAL is one of three PEARL facilities, which include the PEARL Ridge Laboratory and the Surface and Atmospheric Flux, Irradiance and Radiation Extension (SAFIRE). Table 1 lists the ØPAL instruments and their respective capabilities.

Figure 2 shows ØPAL and highlights the two instruments of interest here: the Arctic High Spectral Resolution Lidar (AHSRL) and the Millimeter-wave Cloud Radar (MMCR). The instruments are housed in climate-controlled shipping containers which are powered by a diesel generating station that is $215 \mathrm{~m}$ to the south. The measurements from each instrument are transmitted from Eureka by satellite link, and 
Table 1. Instrument complement and measurement capabilities at ØPAL.

\begin{tabular}{ll}
\hline Instrument & Measurements \\
\hline Arctic High Spectral Resolution lidar (AHSRL) & $\begin{array}{l}\text { Particle optical properties including depo- } \\
\text { larization }\end{array}$ \\
Millimeter-wave Cloud Radar (MMCR) & Cloud reflectivity and Doppler velocity \\
Atmospheric Emitted Radiance Interferometer & $\begin{array}{l}\text { Zenith infrared spectral radiances } \\
\text { (AERI) }\end{array}$ \\
CANDAC Raman Lidar (CRL) & $\begin{array}{l}\text { Particle optical properties, temperatures } \\
\text { and water vapor }\end{array}$ \\
Tropospheric Ozone Lidar & Ozone concentration \\
Microwave Radiometer & Water vapor column \\
CIMEL Sun photometer & $\begin{array}{l}\text { Aerosol optical depth and column size dis- } \\
\text { tribution }\end{array}$ \\
Star photometer & Aerosol optical depth \\
\hline
\end{tabular}

are archived by CANDAC. Data from both the AHSRL and MMCR can be accessed through the University of Wisconsin's lidar group web site: http://lidar.ssec.wisc.edu/.

\subsection{Arctic High Spectral Resolution Lidar}

The Arctic High Spectral Resolution Lidar (AHSRL) was developed at the University of Wisconsin and is supported at PEARL by NOAA's SEARCH program. It has collected quasi-continuous data at Eureka from August 2005 to present, with occasional down time due to maintenance requirements. The instrument is an Internet appliance designed for unattended operation. Technical specifications for the AHSRL are presented in Table 2.

The transmitter consists of a frequency-doubled diodepumped Nd:YAG laser emitting at a $4 \mathrm{kHz}$ repetition rate and $532 \mathrm{~nm}$ wavelength. The laser is seeded and locked using an iodine vapour cell so that the frequency of the light is stable and the line width is narrow. The outgoing beam is circularly polarized and is transmitted at a $4^{\circ}$ zenith angle to avoid specular reflections from horizontally-oriented ice crystals. A $40 \mathrm{~cm}$ telescope is used by both the transmitter and receiver. The receiver's $45 \mu \mathrm{rad}$ field of view significantly reduces the background light level and contributions from multiple scattering. Incoming photons are separated according to polarization state, and are filtered using a $0.35-\mathrm{nm}$ bandpass interference filter and a $8-\mathrm{GHz}$ bandpass pressure-tuned etalon. Signal detection is performed using Geiger-mode avalanche photodiodes and photon-counting electronics. Additional technical details are given by Razenkov et al. (2002).

The lidar measures the particle backscatter cross-section $\left(\beta_{\text {lidar }}\right)$ and circular depolarization ratio $(\delta)$. The depolarization may be used to differentiate between spherical liq-

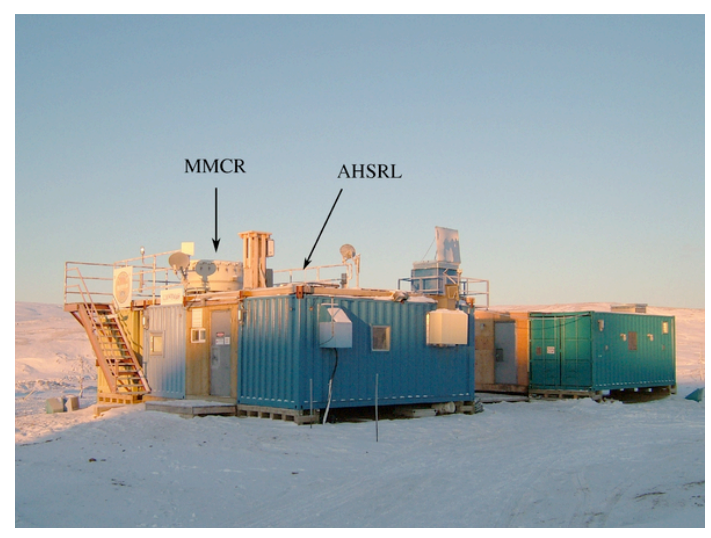

Fig. 2. A photograph of the Zero-altitude PEARL Auxiliary Laboratory (ØPAL) with pointers to the Arctic High Spectral Resolution Lidar (AHSRL) and Millimeter-wave Cloud Radar (MMCR) locations.

uid droplets and crystalline particles, which have low and high depolarization values, respectively (e.g., see Intrieri and Shupe, 2004). Appropriate thresholds for the interpretation are established in this study.

The AHSRL data employs $2.5 \mathrm{~s}$ temporal and $7.5 \mathrm{~m}$ spatial resolutions and can measure volume backscatter crosssection profiles up to an optical depth of approximately 4 , beyond which the transmitted beam is too attenuated. In this work, $30 \mathrm{~s}$ and $15 \mathrm{~m}$ averaged measurements are used. The standard deviation for each average (determined from the intrinsic resolution data) is employed to filter out data with excessive atmospheric variability or noise. 
Table 2. AHSRL specifications.

\begin{tabular}{ll}
\hline & Transmitter \\
\hline Type & Diode-pumped seeded Nd:YAG laser \\
Wavelength & $532 \mathrm{~nm}$ \\
Avg. power & $200 \mathrm{~mW}$ \\
Spectral width & $<1 \mathrm{pm}$ \\
Rep. Rate & $4 \mathrm{kHz}$ \\
Beam diameter & $0.4 \mathrm{~m}$ \\
\hline & \multicolumn{1}{c}{ Receiver } \\
\hline Field of view & $45 \mu \mathrm{rad}$ \\
Spectral bandpass & $8 \mathrm{GHz}$ pressure tuned etalon \\
Aperture & $0.4 \mathrm{~m}$ \\
Data acquisition & Photon counting \\
Detectors & Geiger-mode APDs \\
Spatial resolution & $7.5 \mathrm{~m}$ \\
Temporal resolution & $2.5 \mathrm{~s}$ \\
Range & $75-30000 \mathrm{~m}$ \\
\hline
\end{tabular}

\subsection{Millimeter-Wave Cloud Radar}

CANDAC's Millimeter-wave Cloud Radar (MMCR) is colocated with the AHSRL. This type of radar is effective for cloud microphysics studies because it combines high sensitivity and high vertical spatial resolution. With a wavelength of $8.6 \mathrm{~mm}$, the scattering from atmospheric particles is in the Rayleigh regime and thus has a strong dependence on the particle size.

Compared to wind profiling and precipitation surveillance radars (wavelengths from 3 to $600 \mathrm{~cm}$ ), millimeter wavelength radars have the advantage of increased sensitivity to smaller particles, but the disadvantage of strong attenuation from rainfall. This disadvantage is not relevant during the cold High Arctic winter since the only precipitation is frozen. Snowfall and ice crystals attenuate the radar signal minimally. Water vapor also has negligible impact since the wintertime Arctic atmosphere is relatively dry.

The MMCR has been collecting data since August 2005 and is designed for remote operation with an intended lifetime of at least 10 years. It provides information on Doppler velocity, spectral width and radar reflectivity. The latter can be related to the backscattering cross-section of the atmospheric particles, which allows direct comparison with the AHSRL backscatter measurements.

Technical specifications for the MMCR are given in Table 3. The general setup of the system is similar to that of the lidar with a coaxial, vertically pointing transmitter and receiver. The instrument employs a frequency converter which produces $34.86 \mathrm{GHz}$ microwaves from the internal $60 \mathrm{MHz}$ frequency waveforms. Pulses are emitted vertically by a $2 \mathrm{~m}$ diameter high-gain antenna. The antenna also acts as the receiving apparatus. The measured return signal is converted to $60 \mathrm{MHz}$ frequency and analyzed by a commercial
Table 3. Millimeter-wave Cloud Radar (MMCR) specifications.

\begin{tabular}{ll}
\hline & Transmitter \\
\hline Type & Travelling wave tube \\
Lifetime & $>20000 \mathrm{~h}$ \\
Wavelength & $8.6 \mathrm{~mm}($ Frequency=34.86 GHz) \\
Avg. power & up to $25 \mathrm{~W}$ \\
Beam width & $0.3^{\circ}$ \\
\hline & Receiver \\
\hline Type & Tilted flat radome Antenna \\
Diameter & $1.8 \mathrm{~m}$ \\
Sensitivity & approx. $-40 \mathrm{dBZ}$ at $10 \mathrm{~km}$ \\
Spatial resolution & $90 \mathrm{~m}$ \\
Temporal resolution & $10 \mathrm{~s}$ \\
Range & $90-20000 \mathrm{~m}$ \\
\hline
\end{tabular}

data system from NOAA. Doppler velocities and reflectivity/backscatter cross-sections are retrieved.

The millimeter-wave pulses can be compressed to improve the instrument's sensitivity and power. This has the disadvantage of creating sidelobe artifacts, especially in regions where reflectivity is strong. In order to get the best data product possible, the MMCR cycles through four signal acquisition modes with different pulse width and pulse-encoding. Combination of these modes allows for optimization of the signal through increased sensitivity while accounting for the artifacts. Details are given by Moran et al. (1998).

The MMCR measures reflectivity from $90 \mathrm{~m}$ to $20 \mathrm{~km}$ in altitude, and is sensitive to volume backscatter cross-sections greater than $10^{-14} \mathrm{~m}^{-1} \mathrm{sr}^{-1}$. Data are recorded with a temporal and spatial resolution of $10 \mathrm{~s}$ and $90 \mathrm{~m}$, respectively. For the purposes of this study, the data are interpolated to the same resolutions used by the averaged lidar measurements (30 $\mathrm{s}$ and $15 \mathrm{~m})$.

\section{Methodology}

\subsection{Categorization process and statistical analysis}

Particle observations in the measurement record were visually divided into four categories based upon the identification of structural features in time and height with some attention to optical properties. Visual inspection was used because it is normally straight-forward to identify features "by eye" and also because the elimination of category cross-contamination is required. Scattering events that could not be readily identified were excluded from further analysis. The approach is illustrated below using the example measurement given in Fig. 3. Following particle classification, the statistics of scattering properties in each category are determined and compared with the same statistics for the entire measurement record. 


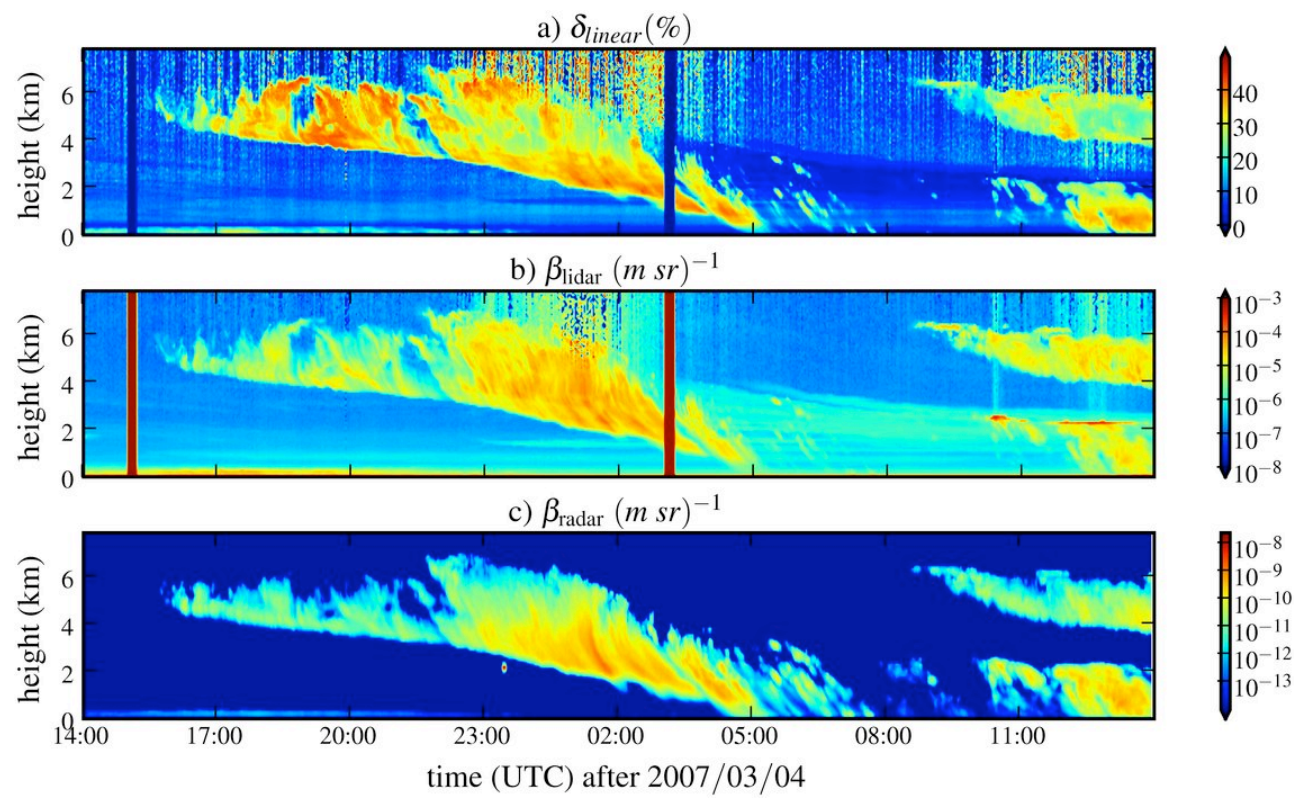

Fig. 3. Example of time series from 4 to 5 March 2007 of (a) depolarization, (b) lidar volume backscatter cross-section, and (c) radar backscatter cross-section.

Figure 3 shows a sample $24 \mathrm{~h}$ measurement on 4 5 March 2007 from the AHSRL and MMCR, selected from the hundreds of such measurements used in this study. The image reveals clouds and aerosols that are well-observed throughout their entire vertical extent. Such complete viewing requires the optical depth to be relatively low $(\lesssim 2)$, which is generally the case at Eureka during winter. Clouds in the other seasons often have greater liquid water content and so are more optically thick.

From 14:00 to 24:00 UTC, ice crystals (high backscatter, high depolarization) were detected in the lowest $0.5 \mathrm{~km}$ by both the radar and the lidar. Surface-based ice crystals are frequently observed, and are readily distinguished from the other ice crystal types; see Lesins et al. (2009a) for some case studies. Ice clouds (high backscatter, high depolarization) with vertically-aligned fall streaks were present in the middle troposphere from approximately 16:00 to 08:00 UTC, and ended by precipitating to the surface. These cirrus-like clouds occur in the same temperature range (approximately 210-250 K) found in the upper half of the midlatitude troposphere. An aerosol event (low backscatter, low depolarization) between 1 and $4 \mathrm{~km}$ altitude began at 03:00 UTC, and can be distinguished from ice clouds by the horizontallyaligned striations, or sometimes homogenous haze-like character. Note that the aerosol event is largely unseen by the radar, as aerosols are relatively weak scatterers in comparison to clouds. A mixed-phase cloud appeared within the aerosol layer at approximately 10:00 UTC and persisted through the end of the measurement. "Mixed-phase" is the term used to describe a geometrically thin water cloud with ice precipitation below. The water component is identified by enhanced lidar backscatter with low depolarization, whereas the ice precipitate has high depolarization and verticallyaligned fall streaks. The altitude of the thin water cloud corresponds to the top of the inversion layer as measured by the 12:00 UTC radiosonde (not shown). Ice clouds were seen again above $4 \mathrm{~km}$ from 09:00 to 14:00 UTC, with similar character as before. Noise is evident at the upper altitudes in the depolarization ratio measurement between 23:00 and 03:00 UTC, and to a lesser extent in the backscatter crosssection measured by the lidar. Such noise is removed from further analysis by a filtering process described later.

As in the example, scattering events from all measurements in the three complete winters between 2005 and 2008 were visually partitioned into the same four categories: aerosols, mixed-phase clouds, ice clouds and boundary-layer ice crystals. The categories were determined after careful consideration of the entire measurement record. "Boundary layer" here refers to the lowest few kilometers of troposphere influenced by the thermal inversion. No distinction is made between a cloud and its precipitate.

Events identified on each image were visually selected using a mask with $1 \mathrm{~km}$ vertical and $1 \mathrm{~h}$ time resolution. The low resolution used for the mask was deliberate, and ensures that there is enough vertical distance and time gap between different events to avoid cross-contamination. For example, cases with mixtures of different ice crystal types (e.g., precipitation into boundary-layer ice crystals) were removed from the analysis. Mixtures with aerosol particles, however, were always included. Aerosol events are very common and, 
more importantly, the presence of aerosols is difficult to ascertain when other atmospheric phenomena (e.g., blowing snow residuals, ice crystal precipitation) are present. Finally, mixed-phase clouds that were observed to fully glaciate were not re-interpreted as boundary-layer ice crystal events.

The lidar and radar data were filtered to ensure low atmospheric variability and noise within an averaging volume. The lidar data were used to establish the filtering criterion for both instruments given the lidar's higher intrinsic spatial and temporal resolution. Measurements in an averaging volume with a relative standard deviation in the $532 \mathrm{~nm}$ backscatter cross-section greater than $25 \%$ were excluded from further analysis.

The individual high-resolution data points (i.e., averaging volumes) of measurements in each collection were then used to compile two-dimensional histograms of scattering properties. It is from the histograms that the particle statistics are determined. All histograms were normalized so that the total probability is one. Histograms with logarithmic horizontal axes have uniform bin sizes in the logarithmic space so that scattering at the full range of available scales is represented.

\subsection{The colour ratio}

The ratio of the radar and lidar volume backscatter crosssections gives the colour ratio, a derived quantity that is is a proxy for particle size (see Sect. 3.3). The volume backscatter cross-section $(\beta)$ is related to the particle backscatter cross-section $\sigma_{\pi}(r)$ and number density $n(r)$ of particles with radius $r$ by

$\beta=\int_{0}^{\infty} \sigma_{\pi} n d r$

The mean particle cross section $\bar{\sigma}_{\pi}$ is defined by

$\bar{\sigma}_{\pi}=\frac{\int_{0}^{\infty} \sigma_{\pi} n d r}{\int_{0}^{\infty} n d r}$

and the total number of particles $N$ is

$N=\int_{0}^{\infty} n d r$.

Using these, the volume backscatter cross-section can be rewritten as

$\beta=N \bar{\sigma}_{\pi}$

The backscatter cross-section depends on wavelength and so is different for the lidar and the radar. Taking the ratio between the two backscatter cross-sections gives the colour ratio as

$\frac{\beta_{\text {radar }}}{\beta_{\text {lidar }}}=\frac{N \bar{\sigma}_{\pi}\left(\lambda_{\text {radar }}\right)}{N \bar{\sigma}_{\pi}\left(\lambda_{\text {lidar }}\right)}=\frac{\bar{\sigma}_{\pi}\left(\lambda_{\text {radar }}\right)}{\bar{\sigma}_{\pi}\left(\lambda_{\text {lidar }}\right)}$.

Equation (1) has no explicit dependence on number density, and so colour ratio is an average property for particles in a measurement volume.
Practical application of Eq. (1) requires that $\beta_{\text {radar }}$ and $\beta_{\text {lidar }}$ exceed the minimum thresholds of detection for each instrument. Figure 3 demonstrates that this requirement is not satisfied for aerosols, which are generally invisible to the radar. The radar's insensitivity to very small particles follows from Fig. 3b, which shows a maximum lidar volume backscatter cross-section for aerosols is $10^{-5} \mathrm{~m}^{-1} \mathrm{sr}^{-1}$. Using Mie theory (see Sect. 3.3), the colour ratio for the submicron particles in Arctic haze (e.g., Leaitch et al., 1989) is about $10^{-12}$, leading to an expected radar volume backscatter cross-section of $10^{-17} \mathrm{~m}^{-1} \mathrm{sr}^{-1}$. This is three orders of magnitude less than the edge of detectability by the radar. In other words, the aerosol cloud concentrations would need to be at least 1000 times greater than the maximum observed under normal circumstances to be seen by the radar. Since aerosol particles cannot be detected with both instruments, an interpretation in terms of particle size is not possible. Aerosols will, however, continue to be considered in terms of optical scattering properties and their potential for mixing with other scatterer types. Note that although there are similar detectability issues for polar cloud particles with the CloudSat radar and CALIPSO lidar satellite instruments (e.g., Grenier et al., 2009), Fig. 3 suggests that is not the case here.

Figure 4 shows the colour ratio for the measurement given in Fig. 3. The colour ratio measurement reveals substantial temporal and spatial structure. For mid-tropospheric ice clouds, fall streaks with relatively large particle sizes (i.e., colour ratios) are apparent. Of particular interest is that the particles are often larger near cloud bottom, an observation that is established statistically in Sect. 5.2.1. Note that the aerosol event that occurred between 2 and $4 \mathrm{~km}$ altitude after 03:00 UTC is largely absent.

\subsection{Particle effective radius and interpretation}

Mie scattering theory can be used to convert the colour ratio to spherical particle effective radius $r_{\text {eff }}$ defined by

$r_{\mathrm{eff}}=\frac{\int_{0}^{\infty} n(r) r^{3} d r}{\int_{0}^{\infty} n(r) r^{2} d r}$

where $r$ is the radius, and $n(r)$ is the number density. The interpretation of effective radius in terms of actual particle dimensions will be discussed shortly. We employed the algorithms from Mishchenko et al. (2002) to determine mean particle backscatter cross-sections $\bar{\sigma}_{\pi}$ for distributions of spherical particles characterized by $r_{\text {eff }}$ and effective variance $v_{\text {eff }}$ given by

$v_{\text {eff }}=\frac{\int_{0}^{\infty} n(r)\left(r-r_{\mathrm{eff}}\right)^{2} r^{2} d r}{r_{\text {eff }}^{2} \int_{0}^{\infty} n(r) r^{2} d r}$.

The effective radius and variance are used in our analysis because the results for colour ratio are relatively insensitive to the specific distribution of particles used. For example, although our calculations have assumed a gamma distribution 


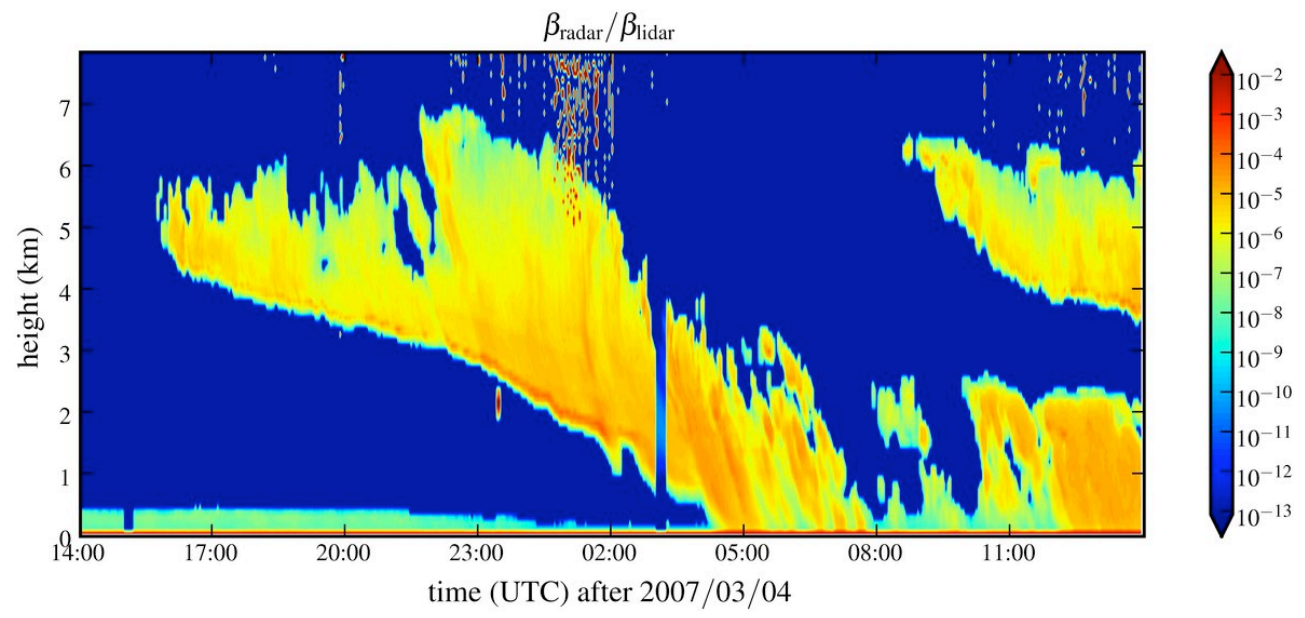

Fig. 4. The colour ratio $\left(\beta_{\text {radar }} / \beta_{\text {lidar }}\right)$ for the measurement in Fig. 3.

of particles, we have verified that a modified power-law distribution with the same parameters produces similar results.

The parameters required for the Mie calculations include the particle refractive index and the wavelength of the incident light. Table 5 gives the choices used in this study. The refractive index $n_{i}$ is wavelength dependent, and in the case of radar waves has a large imaginary part for water droplets which implies a strong absorption component.

Figure 5 presents the results of the Mie computations. Curves are given for ice and water particles for a selection of $v_{\text {eff }}$ values. The plot allows conversion of colour ratios to effective radii ranging from 1 to more than 100 microns once a choice of particle type and $v_{\text {eff }}$ is made.

The particle effective radii discussed hereafter were computed using $v_{\text {eff }}=0.1$. This choice of effective variance is relatively narrow and produces colour ratio curves that smoothly interpolate those obtained with monodisperse distributions. The choice of narrow distributions is appropriate given the high spatial and temporal resolutions in use, and the corresponding high degree of variability revealed in the colour ratios of Fig. 4. In the case that the actual distributions have greater effective variance, say 0.3 , the maximum systematic error expected in our effective radius estimates is less than $+25 \%$.

Computations may also be performed for non-spherical particles, but were not pursued here because we have no information on particle habit. Depolarization cannot be used as an unambiguous detector of ice particle shape, and so the incorporation of depolarization into the present analysis is not possible. Furthermore, the range of particle morphologies in ice clouds is varied and rarely pristine (Korolev et al., 1999), and so choosing any one particle type is arbitrary.

Instead, we focus on the interpretation of effective radius measurements in terms of observed particle shapes. Mahesh et al. (2001) demonstrated that effective radii determined

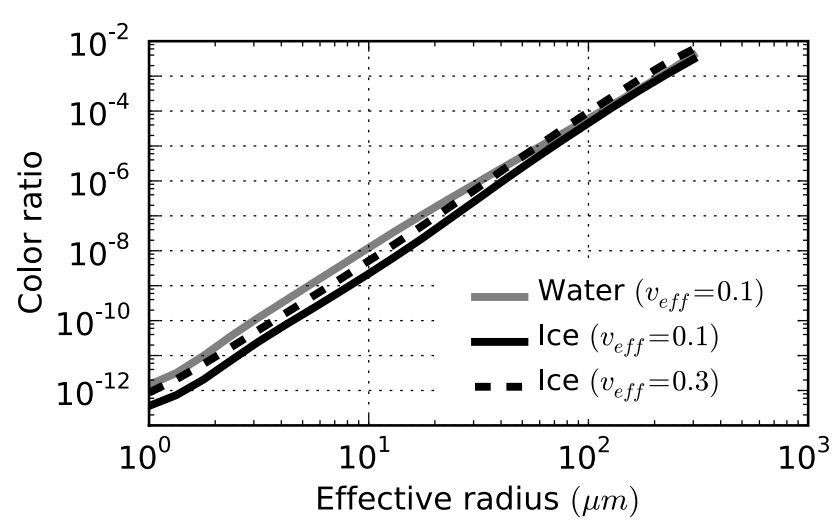

Fig. 5. The relationship between effective radius and colour ratio determined using Mie scattering theory for ice and water spheres.

from infrared remote sensing agree with radii for equivalent volume-to-area (V/A) spheres from sampled ice crystals. In a series of papers, Grenfell et al. (1999), Neshyba et al. (2003) and Grenfell et al. (2005) showed that the equal-V/A sphere diameter is characteristic of the smallest dimension for a variety of realistic particle types. For example, the equal-V/A diameter is comparable to a column particle's width rather than its length. They also argued that the equal-V/A radius is of high importance for radiative transfer. In the comparisons that follow, we will therefore consider our effective radius determination to be associated with the smallest particle dimension.

Our approach differs from some others found in the literature, and takes advantage of the unique capabilities of the AHSRL and MMCR in a low optical depth and dry environment. More complicated methods are necessary when the backscatter cross-sections cannot be so directly measured 
(see Donovan et al. (2001), for example). Alternative derivations of particle sizes can be made in terms of cloud extinction using the Raman lidar technique (e.g., Wang and Sassen, 2002), but much longer integrations are required to achieve an appropriate signal-to-noise level, and so they are not of interest here.

\section{Results}

\subsection{5-2008 Data set}

Figure 6 shows two-dimensional histograms of occurrence probability against scattering parameters and altitude for the full data set spanning the wintertime months of December through March of 2005 to 2008. $7772 \mathrm{~h}$ of measurements over 351 days were used. The distributions contain the signatures of liquid water droplets, aerosols, ice crystals, and particle mixtures. Dissimilar scatterers occupy separate regions in each histogram, as will be shown using the categorized data sets. The full histograms can be used to determine the relative contribution from each scatterer type.

Figure 6a shows the probabilities for depolarization against altitude. There are features in the distribution found below $10 \%$ and above $20 \%$ linear depolarization, which correspond to predominantly liquid and ice scatterers, respectively. Ice scatterers extend from the ground up to at least $8 \mathrm{~km}$ in altitude. Liquid scatterers are mostly found near the ground, except for a small population peaking near $2 \mathrm{~km}$ altitude with linear depolarization less than $3 \%$. The near-ground low-depolarization events are associated with aerosols, and the linear depolarizations less than 3\% represent droplets in thin water clouds, as will be shown in the sections that follow.

Figure $6 \mathrm{~b}$ shows the probabilities for colour ratio (a proxy for particle size) against altitude. There is a trend toward smaller particles (i.e., smaller $\beta_{\text {radar }} / \beta_{\text {lidar }}$ ) with increasing height. Figure $6 \mathrm{c}$ shows the probabilities for colour ratio against depolarization. The strong maximum between 15 and 50\% linear depolarization is due to ice scatterers, and the low-depolarization "tail" (below 10\%) is for mostly liquid scatterers. Notice that ice scatterers (high depolarization) are larger than the liquid scatterers (low depolarization).

Figure 7 shows separate histograms for each category in columns: Aerosols, mixed-phase clouds, ice clouds, and boundary-layer ice crystals. Each category is discussed in respective subsections that follow.

\subsection{Aerosols}

$1199 \mathrm{~h}$ of measurements over 103 days were categorized as aerosol scattering. Before analyzing the histograms in Fig. 7, we briefly consider Fig. 8 which provides a histogram for aerosols using all available detections by the lidar. Aerosols are observed to occur mostly below 2 or $3 \mathrm{~km}$ in altitude, with depolarization values ranging from 0 to 20 or $30 \%$. The
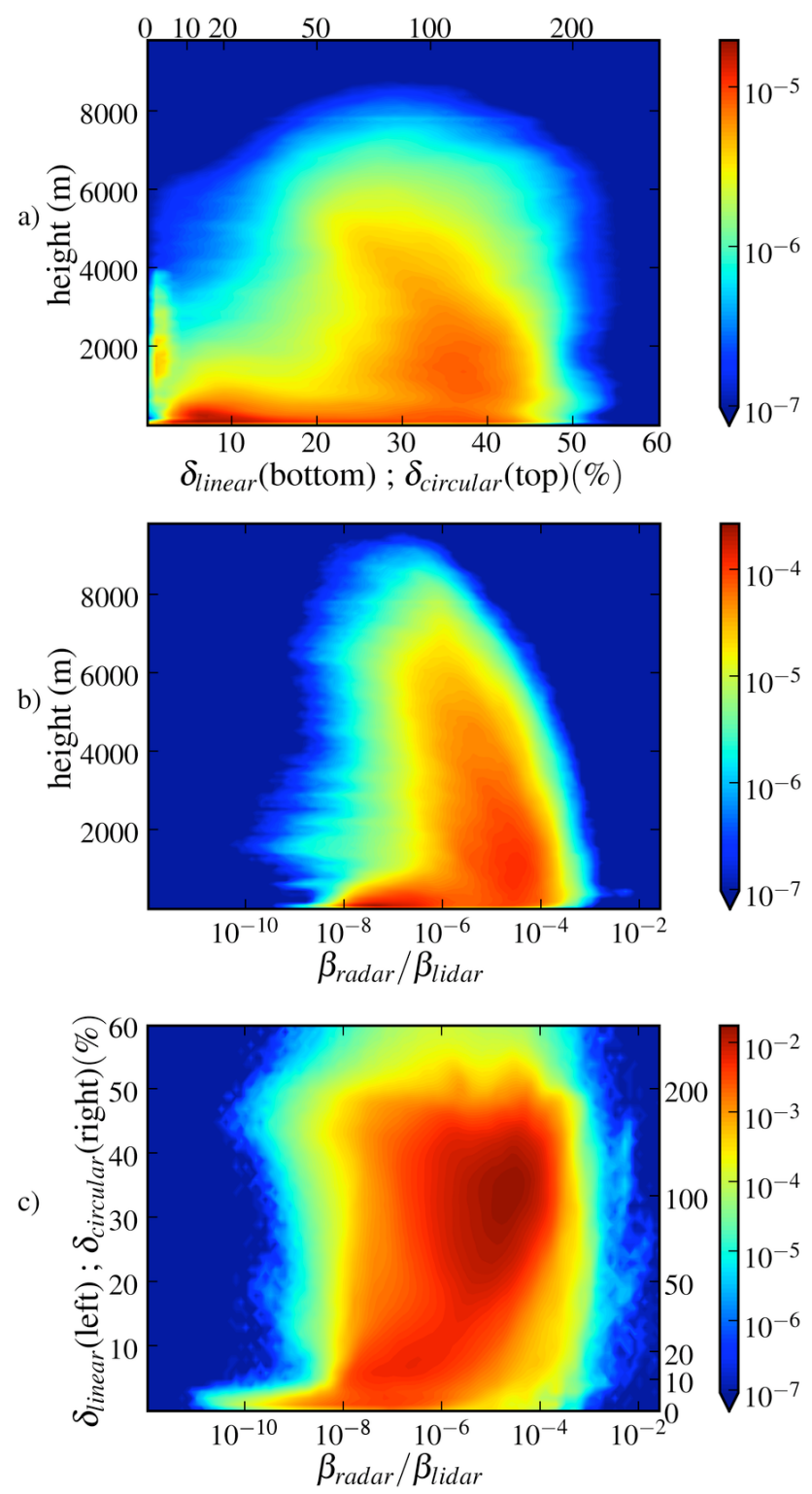

Fig. 6. Average occurrence probability histograms during winter (2005-2008) for (a) the vertical distribution of depolarization, (b) the vertical distribution of the colour ratio, and (c) the colour ratio and depolarization. Detections by both lidar and radar were required.

larger depolarization values are due to the presence of ice crystals. Vertical discontinuities in the figure are an artifact of the categorization process, which used $1 \mathrm{~km}$ resolution.

Figure 7a provides histograms using the subset of aerosol measurements for which both lidar and radar detections are available. Since aerosols are nearly ubiquitous in the Arctic atmosphere, distributions in this column will help to identify aerosol contamination in the ice particle categories. Although aerosols are generally not detected by the radar, the 

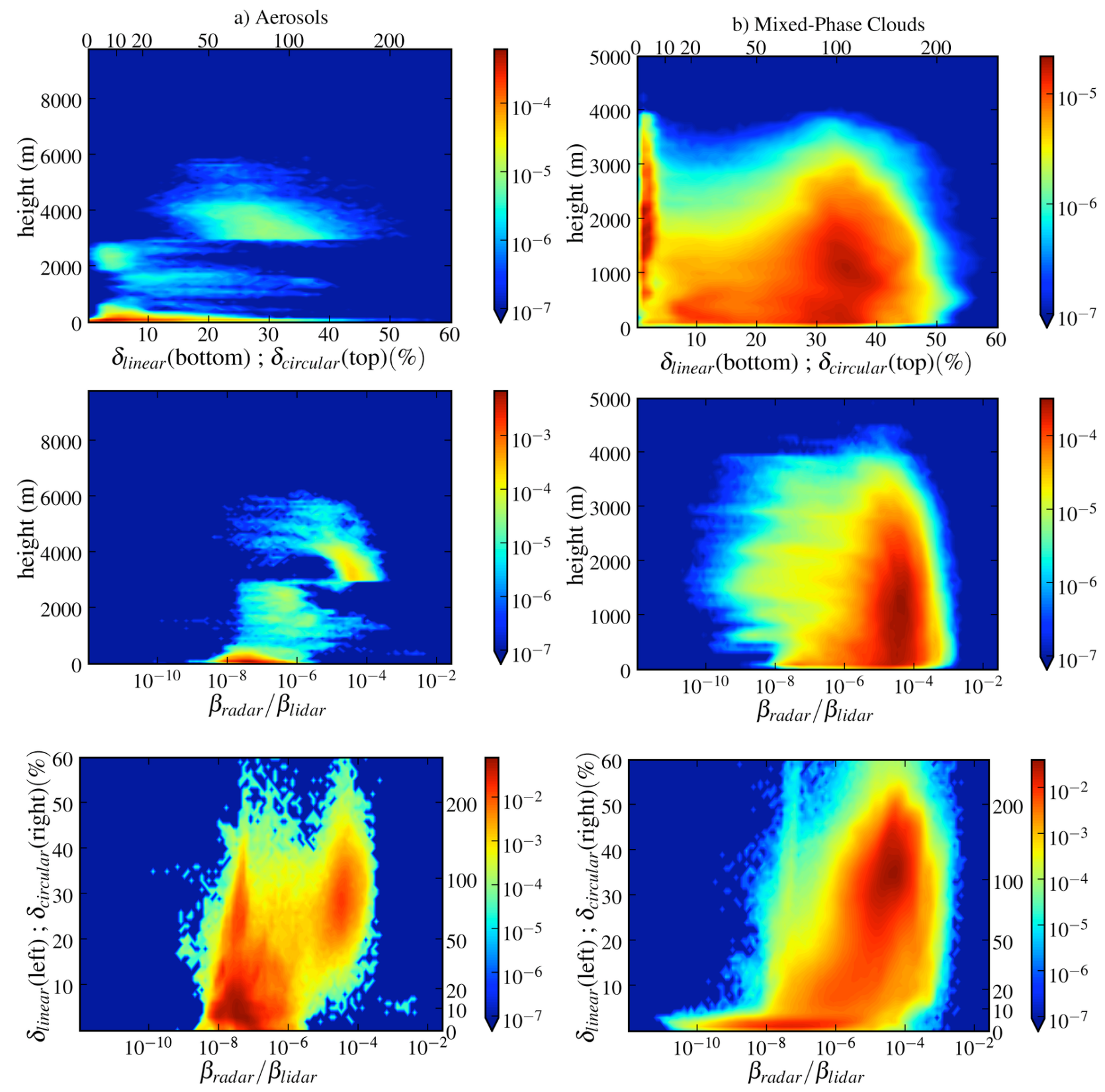

Fig. 7. Occurrence probability histograms arranged in columns for (a) aerosols, (b) mixed-phase clouds, (c) ice clouds, and (d) boundarylayer ice crystals. Detections by both lidar and radar were required.

presence of a small quantity of ice crystals can easily elevate the backscatter cross-section above the detection threshold. Ice crystals are relatively large, and radar reflectivity is proportional to the sixth power of individual particle diameters. In the case of particle size distributions, empirical relations show reflectivity is proportional to the 3.8th power of the median volume diameter (Brown and Francis, 1995; Matrosov et al., 2002). In any event, relatively few ice crystals can add substantially to the aerosol backscatter.
The top panel of Fig. 7a shows most of the dual lidar-radar aerosol detections occur near ground. This is different from what is seen in Fig. 8, and reflects the fact that ice scatterers are also ubiquitous at the lowest altitudes. Fewer detections were made higher up, and the coarseness of the distribution reflects low-probability statistics. Surface-based aerosols have linear depolarization between 0 and $20 \%$, which is similar to that seen in Fig. 7. Relatively high depolarizations away from the surface indicate a dominant contribution from ice crystals. 

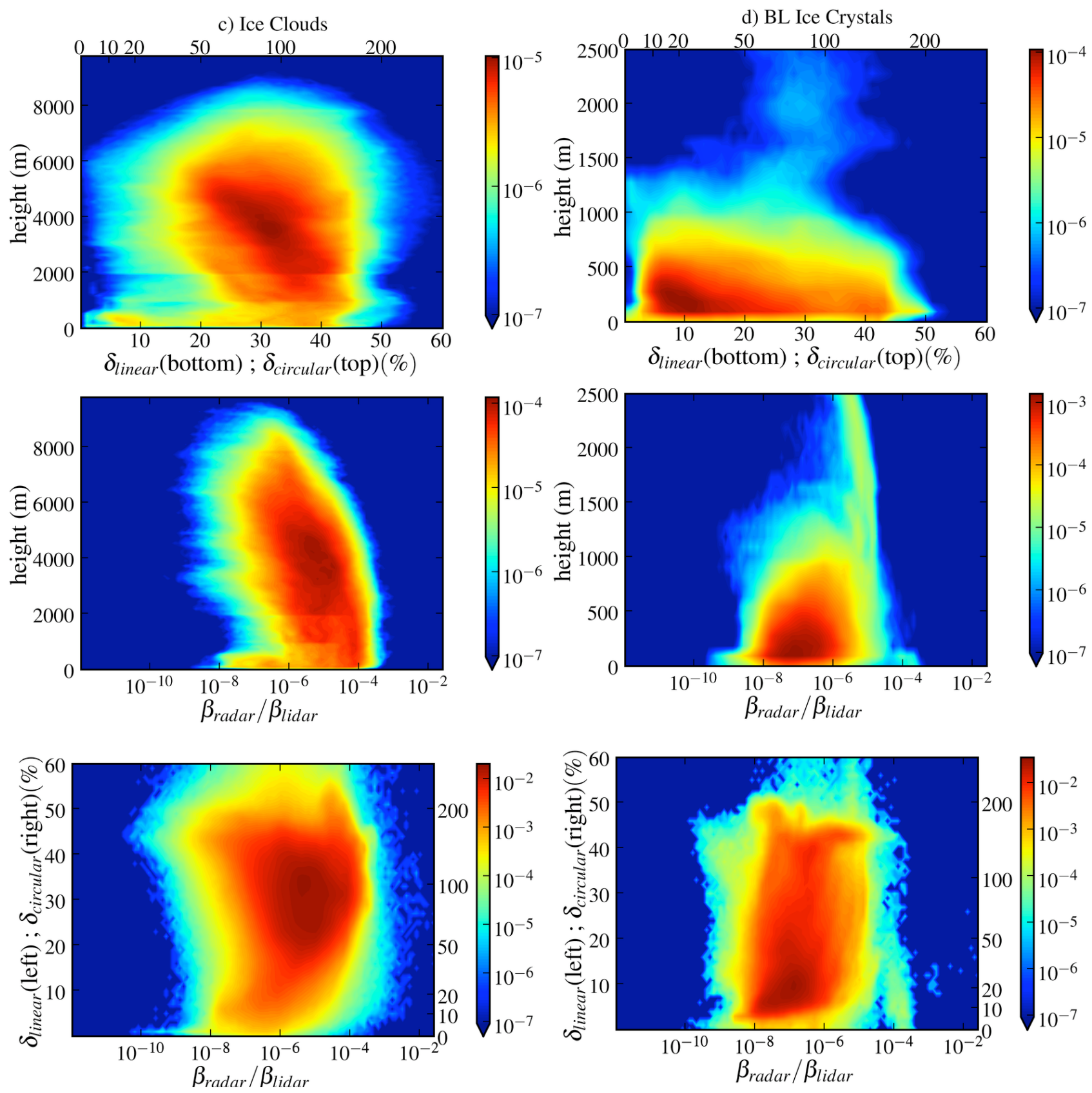

Fig. 7. Continued.

The middle panel of Fig. 7a indicates that aerosol contamination of the other plots in Fig. 7 can be expected primarily at the surface. Similarly, the lower panel indicates that aerosol contamination for depolarizations below $10 \%$ and for colour ratios between $10^{-8}$ and $10^{-7}$ will be an issue. This corresponds to the "tail" region mentioned in the description of Fig. 6. Note that depolarization values larger than $10 \%$ in the bottom panel of Fig. 7a are representative of ice scattering, and so would not be considered a contamination in the other columns.

\subsection{Mixed-phase clouds}

$894 \mathrm{~h}$ of measurements over 86 days were used to compile the histograms for mixed-phase clouds shown in Fig. 7b. The distinction between water droplets and ice crystals is evident in the top panel, which shows the depolarization versus altitude. Near-zero values of depolarization extending from $500 \mathrm{~m}$ to $3.5 \mathrm{~km}$ in altitude are due to droplets in thin water clouds. High linear depolarizations of 20 to $50 \%$ are from the frozen condensate, and are found largely below 


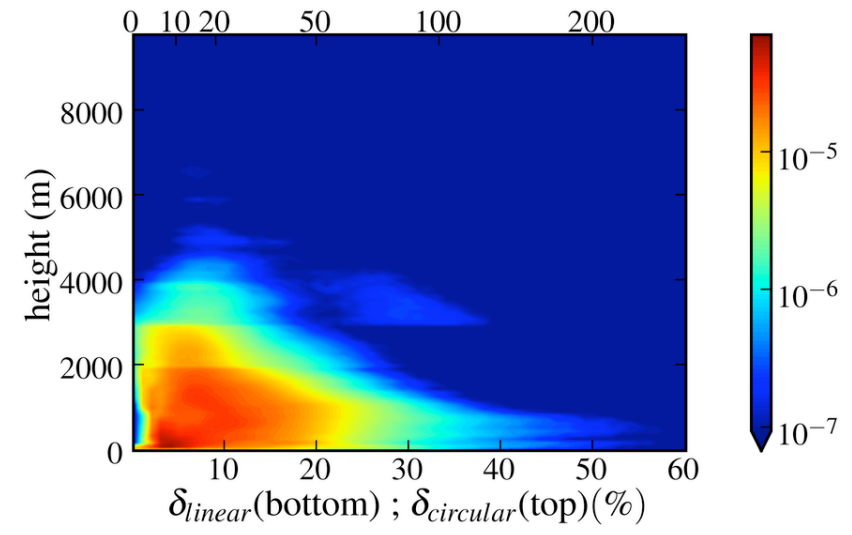

Fig. 8. Occurrence probability histogram for aerosols against height and depolarization, using all available lidar detections. The step changes apparent in the figure at $1 \mathrm{~km}$ intervals are a result of the event masking process, and cannot be eliminated due to the ubiquity of aerosols in the Arctic atmosphere.

the liquid component heights as would be expected for precipitate. There is a region of intermediate linear depolarization between 3 and $20 \%$ which corresponds to the transition region from liquid to ice. The local maximum near ground at $10 \%$ depolarization represents a contribution from the aerosols, as established in the top panel of Fig. 7a.

The vertical distribution of probabilities against colour ratio in the middle panel has horizontal streaks for colour ratios between $10^{-9}$ and $10^{-6}$ which are from the thin water clouds. The dominant scattering maximum is for ice crystals, which at high colour ratio have much larger sizes than the water droplets. Note that the population has constant colour ratio with height, which indicates uniform size. The bottom panel, which presents the probabilities against the depolarization and colour ratios, confirms the size comparison between the two scatterer types. The water droplet population (linear depolarization $<3 \%$ ) has much smaller colour ratio values compared to the ice crystal populations (linear depolarization with the greatest part between 20 and 50\%). There is a transition region between the two peaks which can be attributed to the phase change from water to ice.

\subsection{Ice clouds}

$1424 \mathrm{~h}$ of measurements over 134 days were used to compute the histograms for ice clouds given in Fig. 7c. The top panel shows that linear depolarizations range from about 15 to $45 \%$. The mean linear depolarization decreases with height, from approximately $40 \%$ at $2 \mathrm{~km}$ to $25 \%$ at $5 \mathrm{~km}$ altitude. Note that horizontal discontinuities at 1 and $2 \mathrm{~km}$ altitude in this panel are an artifact of the selection process resolution described earlier.

In the middle panel, the mean colour ratio decreases with height. This indicates a decrease of mean ice crystal size with
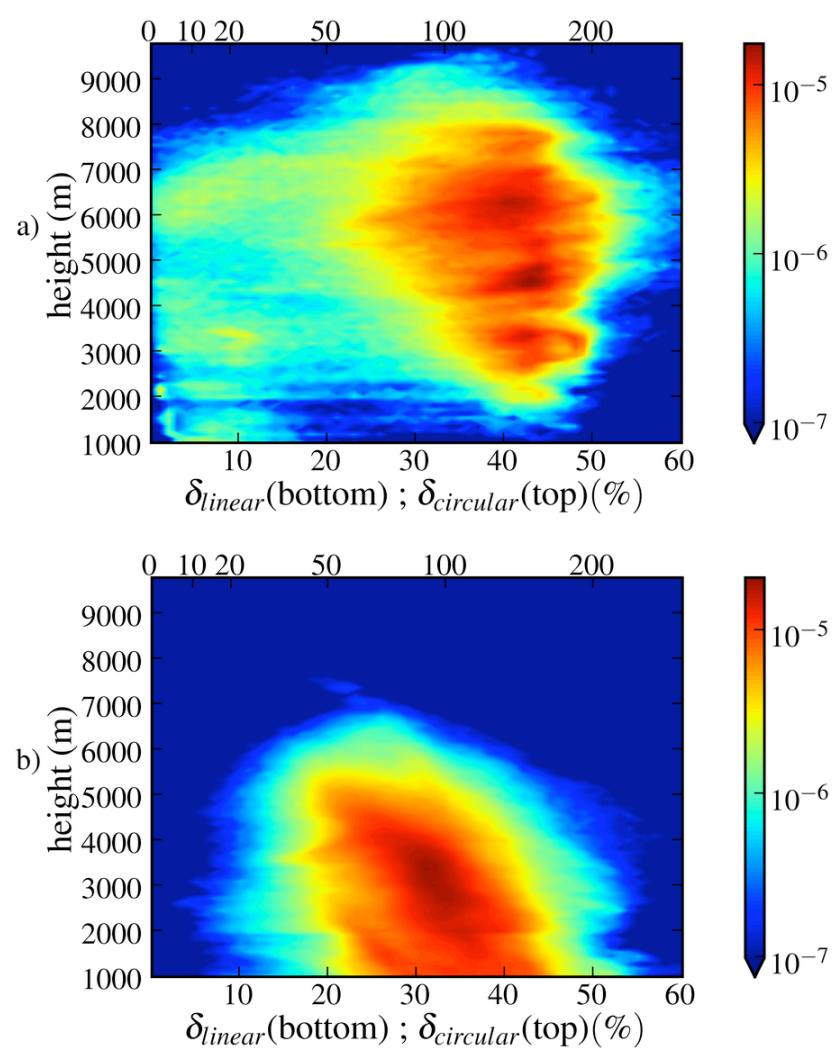

Fig. 9. Occurrence probability histograms for ice clouds against altitude and depolarization for (a) small particles (colour ratios $<10^{-7}$ ), and (b) large particles (colour ratios $>10^{-5}$ ).

height, which is similar to the depolarization trend. Decreasing colour ratio with height is also evident in the example given in Fig. 4. It is interesting to note that small ice particles are evident in approximately equal quantities between 3 and $8 \mathrm{~km}$ altitude. A low colour-ratio contribution from aerosols below $1 \mathrm{~km}$ is apparent.

The bottom panel gives the probabilities against depolarization and colour ratio. The tail at low depolarization extending from the main population is due to aerosols. Although the upper two panels might suggest that depolarization is a function of particle size, the bottom panel indicates that this is not the case. Small ice crystals tend to have high depolarization (40\%-50\%), whereas larger particles span a wide range of depolarization values.

Separate histograms against depolarization and altitude for small and large ice crystal sub-populations are given in Fig. 9. The low-depolarization detections in Fig. 9a represent a contribution from aerosols. The modal depolarization for small ice particles is fairly constant with altitude, although the range of depolarization values become larger with height. This contrasts with large particles that have decreasing depolarization with height (Fig. 9b). The same trend is evident 
when particles of all sizes are included (Fig. 7c, top panel). Further comparison of Fig. 9a and b reveals that small ice particles tend to depolarize more than large ones at a given altitude. This result confirms that decreasing depolarization with height cannot be associated with decreasing size.

\subsection{Boundary-layer ice crystals}

$1338 \mathrm{~h}$ of measurements over 107 days were used to compute the histograms for boundary layer ice clouds. Results are shown in Fig. 7d. The top panel shows that ice crystals are observed mostly below $750 \mathrm{~m}$ altitude. The depolarization spans a large range, including values too low to indicate solid phase. The low-depolarization values are attributed to the presence of aerosols.

The middle panel shows colour ratios that are in the same range as determined for aerosol layers only (Fig. 7a). The calculations were performed again considering data with depolarization values greater than $25 \%$ (i.e., ice crystals only), and a very similar plot was obtained. This confirms that the colour ratio values determined for aerosols (Fig. 7a) are biased by the ice crystals contained within. The bottom panel shows that there is no trend in depolarization with colour ratio, except for at very low depolarization where an aerosol tail is apparent.

\section{Discussion}

\subsection{Scattering properties}

Comparison of the histograms in Figs. 7 and 8 for the different particle types reveals significant differences in colour ratios, optical properties and vertical distribution. However, inspection of the figures also shows that their superposition effectively reproduces the histograms for the complete data set given in Fig. 6. We can conclude that the most important scatterers above Eureka are well represented by the chosen categories, and that Fig. 6 gives their relative contribution to scattering.

Representative values of properties taken from the histograms for each category are given in Table 4, with effective radius estimates deriving from the appropriate curves in Fig. 5. The values represent estimates corresponding to $10 \%$ of the peak level or greater in each histogram. The estimates were obtained visually from each panel because interpretation to account for height variations and interference from aerosols is required.

The largest particles observed above Eureka are contained in lower-tropospheric ice clouds and the precipitation from mixed-phase clouds. Ice particles in the middle to upper troposphere are somewhat smaller, and boundary-layer ice crystals are smaller yet. Water droplets in mixed-phase clouds are in general smaller than ice particles, as expected. The size of aerosol particles could not be determined because they are not detected by the radar.
Table 4. Ranges for linear depolarization $\delta_{\text {lin }}$, colour ratio, effective radius $r_{\text {eff }}$ and altitudes $z$ for aerosols, mixed-phase (M-P) cloud water droplets (WD) and ice crystals (IC), ice cloud ice crystals, and boundary-layer (B-L) ice crystals. The ice crystal and water droplet values are from Fig. 7 and the aerosol values are from Fig. 8.

\begin{tabular}{lcccc}
\hline Particle & $\delta_{\text {lin }}(\%)$ & colour ratio & $r_{\text {eff }}(\mu \mathrm{m})$ & $z(\mathrm{~km})$ \\
\hline Aerosols & $<20$ & & & $<3 \mathrm{~km}$ \\
M-P Cloud WD & $<3$ & $10^{-9}-10^{-6}$ & $5-40$ & $0.5-3.5$ \\
M-P Cloud IC & $20-50$ & $10^{-6}-10^{-3}$ & $40-220$ & $0-3$ \\
Ice Cloud IC & $20-50$ & $10^{-7}-10^{-4}$ & $25-120$ & $>3.5$ \\
& & $10^{-6}-10^{-3}$ & $40-220$ & $<3.5$ \\
B-L IC & $>20$ & $10^{-8}-10^{-5}$ & $15-70$ & $<0.7$ \\
\hline
\end{tabular}

Table 5. Values for wavelengths $(\lambda)$ and complex refractive indices $\left(n_{i}\right)$ used in the Mie scattering computations for the lidar and radar. Refractive indices are from Warren and Brandt (2008).

\begin{tabular}{lcc}
\hline & Lidar & Radar \\
\hline$\lambda$ & $532 \mathrm{~nm}$ & $8.6 \mathrm{~mm}$ \\
$n_{i}$ (ice) & 1.31 & $1.8+0.0003 \mathrm{i}$ \\
$n_{i}$ (water) & 1.33 & $5+2.5 \mathrm{i}$ \\
\hline
\end{tabular}

Water droplets have linear depolarizations less than 3\%. Aerosol haze typically has linear depolarization less than $20 \%$, which is different from what is found for liquid droplets alone due to ice content. Ice crystals have linear depolarizations greater than $20 \%$. Water droplets have lower colour ratios than do ice crystals, which indicates the water droplets are smaller. Boundary-layer ice crystals, ice clouds, and ice precipitation from thin water clouds occupy partly overlapping ranges of colour ratio values. Ice crystals precipitating from mixed-phase clouds and lower tropospheric ice clouds generally have greater colour ratios (and therefore sizes) than are observed for boundary-layer ice crystals. Middle tropospheric ice particles have comparable colour ratios to those found in the boundary layer.

Ice clouds have depolarization decreasing with altitude (Fig. 7c, top panel). This trend is associated with large particles (Fig. 9b), and contrasts with the nearly constant modal depolarization for small particles (Fig. 9a). The measurements indicate that the large-particle morphology changes with altitude, perhaps in response to particle breaking or sublimation (see, for example, Whiteway et al. (2004). Small particles have greater depolarization than large particles, for unknown reasons.

\subsection{Comparisons with other measurements}

\subsubsection{Particle effective radii}

Comparison of our measurements with values from the literature is complicated by differences in measurement 
techniques. We have provided histograms of occurrence probability for effective radii measured at high spatial and temporal resolution, whereas in-situ measurements typically provide distributions of number concentration against particle size averaged over a long period of time or distance. However, if our assumption of narrow particle size distributions in each measurement volume is correct, a comparison of effective radii measured using the radar and lidar against the range of particle sizes observed with in-situ techniques is appropriate. Where possible, comparisons are made with the smallest dimension of the sampled particles, which is the approach proposed in Sect. 3.3.

For mixed-phase clouds, Arctic aircraft measurements by Curry et al. (2000) show water droplet sizes that range from about 2 to $47 \mu \mathrm{m}$. Frozen precipitation below the liquid stratus ranges from a few tens to several hundred microns in length (widths were not given). Although the measurements were taken during summer between Barrow, Alaska $\left(71.3^{\circ} \mathrm{N}\right)$ and the SHEBA experiment site $\left(76-78^{\circ} \mathrm{N}\right)$, their results are in reasonable agreement with our values at Eureka $\left(80^{\circ} \mathrm{N}\right)$ of 5 to $40 \mu \mathrm{m}$ and 40 to $220 \mu \mathrm{m}$, respectively. The smaller maximum size we measured for ice crystals can be attributed to the sensitivity of our technique to particle widths rather than lengths. Year-round measurements of water droplet and ice particle precipitation with an MMCR at the NSA-AAO site near Barrow yield characteristic radii of 25 to $500 \mu \mathrm{m}$ from terminal fall speeds (Zhao and Garrett, 2008), and our ice crystal sizes fall within this range.

Comparison data for the ice cloud measurements are difficult to find. Wintertime in-situ aircraft campaign data are not available, presumably due to the difficulties of flying experiments in dark conditions. Summertime clouds in the middle troposphere are often of the mixed-phase variety, and are observed in much warmer conditions. High altitude in-situ cirrus measurements in the Arctic are not available.

Lawson et al. (2001) show one case of a mid-tropospheric cirrus cloud sampled at Barrow Alaska on 29 July 1998 during FIRE ACE. They reported that small particles were found in clumps with very high local concentrations that are interspersed with regions of larger particles in low concentrations. This is consistent with the structured ice clouds seen at Eureka and illustrated by the example in Fig. 4, and justifies our use of relatively narrow particle size distributions. Their insitu measurements revealed particles ranging from less than 10 to hundreds of microns, which is consistent with our measured values of 25 to $220 \mu \mathrm{m}$.

A comparison can also be made with mid-latitude cirrus, which are observed at temperatures similar to the wintertime Arctic mid-troposphere. Aircraft sampling of mid-latitude cirrus by Whiteway et al. (2004) revealed particle sizes ranging from less than 10 to a few hundred microns. Radar/lidar inversions by Donovan and van Lammeren (2002) also yield effective particle sizes up to a few hundred microns in radius. They showed that mid-latitude cirrus have effective radius increasing with increasing temperature, which is con- sistent with our observations of decreasing size with increasing height above the temperature inversion. Whiteway et al. (2004) showed that particle size variations with height are determined by a competition between the growth and sedimentation of large particles with crystal breakage into smaller particles and evaporation. The preponderance of larger crystals at low altitudes in our observations is therefore likely due to growth and/or sedimentation.

Turner (2005) measured crystal sizes in both mixed-phase and pure ice clouds using a ground-based remote-sensing AERI system at the SHEBA site. The effective radii for ice cloud particles ranged between 8 and $100 \mu \mathrm{m}$, with a mode radius of about $26 \mu \mathrm{m}$. This is at the lower end of what we observed $(25-220 \mu \mathrm{m})$. Effective radii for ice crystals in mixedphase clouds were even smaller. This was not considered to be realistic, and was attributed by the authors to differing particle shapes between the two cloud types. They assumed a droxtalhexcolumns model in their retrievals; however, ice crystals in Arctic clouds are known to be highly irregular (Korolev et al., 1999). It seems likely that the smaller crystal size they detected in general is due to the particle-shape assumption. In any event, our results suggest that the effective radii of ice crystals in mixed-phase and boundary-layer ice clouds are similar $(40-220 \mu \mathrm{m})$.

Surface-based in-situ measurements of ice crystal sizes for residual blowing snow are not available for the High Arctic. Walden et al. (2003) obtained measurements with a microscope at the South Pole station of many different ice crystal types during winter. They showed that residual blowing snow crystals have a mean effective radius of $11.9 \mu \mathrm{m}$. Their technique relied on ice crystals landing on a gridded microscope slide, and the larger particles were found to blow off in high winds. Given that blowing snow requires wind, it seems likely that there is a bias toward smaller particle sizes in this particular result. Measurements at the Mizuho Antarctic station with a snow particle counter, which is only sensitive to particles larger than $25 \mu \mathrm{m}$ diameter, reveals blowing snow particles as large as $60 \mu \mathrm{m}$ at $9.6 \mathrm{~m}$ altitude, with even larger ones at lower altitudes (Nishimura and Nemoto, 2005). In contrast, the mean effective radius for diamond dust at South Pole Station is $12.2 \mu \mathrm{m}$ and presumably unbiased. Mahesh et al. (2001) showed excellent agreement between remote sensing estimates of small ice crystals and surface-based in-situ sampling.

Boundary-layer ice crystals measurements at Eureka yield effective radii $(15-70 \mu \mathrm{m})$, which are more consistent with blowing snow than diamond dust. It is possible that diamond dust crystals in the Arctic are larger due to the higher temperatures - see, for example, the diamond dust images provided by Intrieri and Shupe (2004) - but there is very little data that can be used to properly assess this, and observations are complicated by the difficulty of distinguishing the different ice crystal sources. The fact that boundary-layer ice crystal events extend to about the same height as the surrounding topography supports our contention that residual blowing snow 
is the source. Boundary-layer ice crystals contribute a significant portion of the overall particle burden above Eureka (Fig. 6). Our measurements suggest that residual blowing snow lofted from mountainous terrain is likely more important to the overall radiative balance than diamond dust. The radiative impact of blowing snow residuals is explored by Lesins et al. (2009a).

In-situ samples of ice crystals in the Arctic are rare, and observations are complicated by contributions to the ice crystal population from the different sources described in this paper. A rigorous study of ice crystals at the surface like that of Walden et al. (2003) does not exist for the High Arctic, and should be considered a priority for future research.

\subsubsection{Ice crystal altitudes}

Boundary-layer ice crystals are found predominantly below $750 \mathrm{~m}$ altitude, which is comparable to the height of the mountain ridges near Eureka. Lesins et al. (2009a) showed four case studies of topographic blowing snow residuals that share the same vertical distribution. This indicates that blowing snow residuals are the dominant contributor to high optical depth boundary-layer ice crystal populations at Eureka. This result likely extends to other land locations in the rugged High Arctic.

Ice clouds are observed throughout the troposphere during winter. At times these ice clouds, which are generated in the same range of temperatures as cirrus clouds at mid-latitudes, can precipitate to the ground.

The altitude range for thin water stratus $(0.5-3.5 \mathrm{~km})$ is smaller than is observed during other seasons (e.g., Curry et al., 1996). The wintertime range corresponds with the observed variability for wintertime surface thermal inversion layer depths given by Lesins et al. (2009b). This suggests that thin liquid water stratus are connected to the development of wintertime surface inversion layers.

It has been known since Wexler (1936) that cold surface temperatures in the Arctic winter are due to radiative cooling by surface snow and ice. More advanced models of the radiative transfer process (e.g., Curry, 1983) showed that in clear air the surface temperatures should be much lower than is observed, which suggests an important role for particles in determining boundary layer temperatures. Curry (1983) proposed a variety of mechanisms that could contribute to the process. These included the radiative impact of diamond dust and liquid condensate, and mixing by turbulence. A role for diamond dust has been discounted by the measurements of Intrieri and Shupe (2004) and Lesins et al. (2009a), and a role for turbulence has yet to be experimentally investigated. Our measurements support the contention of Intrieri and Shupe (2004) that liquid condensate plays an important role. Although the model of Curry (1983) did not produce the kind of thin liquid water clouds discussed here, the water clouds it simulated suggested the same basic mechanism.

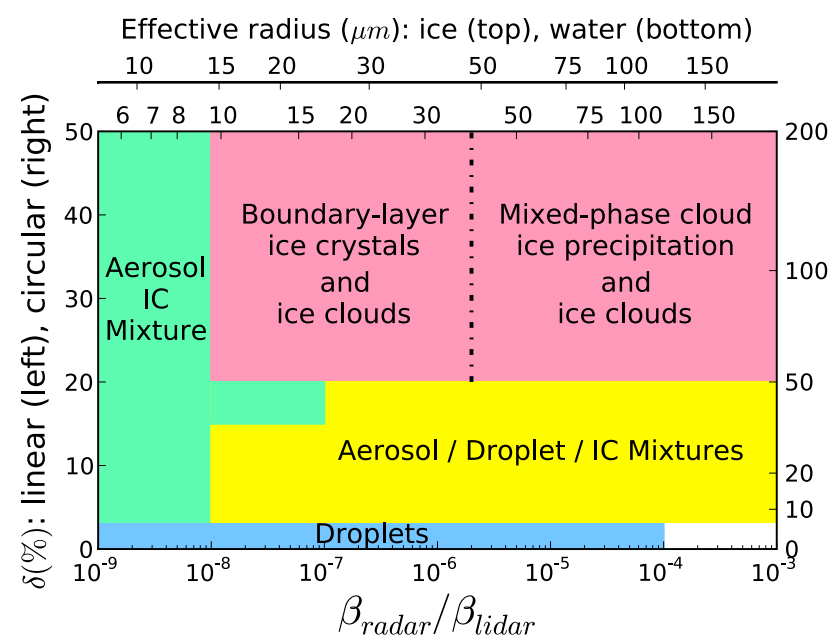

Fig. 10. Classification chart for the different atmospheric particles and their mixtures. The vertical axis shows the linear (left) and circular (right) depolarizations and the horizontal axis is in terms of the color ratio $\beta_{\text {radar }} / \beta_{\text {lidar }}$ (bottom) and the particle effective radius (top) for ice crystals (IC) and water droplets separately. Effective radii can only be attributed to regions with no aerosol content. The dash-dot line separates the boundary layer ice crystals on the left and precipitation from thin water clouds on the right. Ice clouds span the full region for ice crystals.

Thin water cloud dynamics and microphysics are further explored by Shupe et al. (2008).

\subsubsection{Depolarization}

The depolarization of aerosol layers is greater than what is found for liquid droplets. Hoff (1988) showed that ice crystals are responsible for the elevated depolarizations in Arctic haze, and we make the same interpretation here.

Figure 9 established that the depolarization of small particles in ice clouds was greater than for large particles at a given altitude. High depolarization in contrails, which also contain very small particles, was found by Sassen (1997). Young cirrus were shown to have linear depolarization values in excess of $50 \%$. The reasons for this result was unknown to Sassen (1997), as is the case here.

\subsection{Classification chart}

The histograms of Fig. 7 reveal that different scatterer types occupy different regions in particle size-depolarization space. Figure 10 provides a classification chart from the compiled information. The thresholds are approximate, and lead to relatively large regions occupied by particle mixtures. Note that areas with only aerosol particles cannot be interpreted in terms of size or colour ratio because the radar's sensitivity is too low to detect such small particles. 
The lidar volume backscatter cross-section can be used to isolate locations where aerosol layers dominate. The range in lidar volume backscatter cross-section for aerosols is relatively narrow, indicating that variations in sizes and number densities are small. Lidar backscatter cross-sections $\beta_{\text {lidar }}$ that are smaller than $2 \times 10^{-5} \mathrm{~m}^{-1} \mathrm{sr}^{-1}$ are characteristic of aerosol layers and this threshold can be used to distinguish aerosol layers from the mixtures.

In Fig. 10, mixed-phase cloud ice precipitation and boundary-layer ice crystals occupy distinct regions. Ice clouds, however, overlap with both. Some differentiation can be made on the basis of altitude, as shown in Table 4: small ice crystals below $2 \mathrm{~km}$ altitude are generally classified as boundary-layer ice particles, whereas small ice crystals in ice clouds are found predominantly higher up. Ice crystals originating from mixed-phase clouds and ice clouds are indistinguishable on this basis.

\section{Conclusions}

A combined radar-lidar technique was used to study particle properties in the High Arctic troposphere during winter. Different particle types were compared in terms of depolarization, colour ratio, effective radius, and vertical distribution. Colour ratios and effective radii could not be determined for aerosols because they are not detected by the radar, except in mixtures.

Particle effective radii determined using Mie scattering theory are consistent with others found in the literature. Water droplets are small (effective radii of a few tens of microns) while ice particles can be much larger (effective radii up to a few hundred microns). In the boundary layer, mixedphase precipitation and ice cloud snow provide the largest ice crystals whereas residual blowing snow particles lofted from mountain ridges are smallest. Ice cloud crystal sizes have a strong gradient in altitude with the largest particles at the lowest heights. The size ranges for each particle type are summarized in Table 4.

Depolarization is highly dependent on the particle type. Particle scattering dominated by aerosols has linear depolarization less than $20 \%$, whereas ice crystals scattering has linear depolarization greater than $20 \%$. Much of the depolarization in aerosol layers likely originates from ice crystals mixed in. Water droplets, in contrast, have linear depolarizations less than $3 \%$. Ice clouds in the middle troposphere have depolarization decreasing with altitude, and this trend is reflected in the large particle sub-population. Small particles in ice clouds have greater depolarization than large ones at any given altitude, and almost constant modal depolarization with height. The measurements indicate that particle morphology changes with altitude.

Boundary-layer ice crystals contribute significantly to the overall particle burden above Eureka. Their sizes and observed vertical extent indicate that blowing snow residuals lofted from the surrounding mountainous terrain is a more likely source than nucleation of diamond dust. Lesins et al. (2009a) presented case studies that established these blowing snow residuals can have a significant radiative impact. Given that much of the Arctic is similarly mountainous, the regional impact of blowing snow residuals on the infrared radiative transfer will need to be assessed.

Thin water layers associated with mixed-phase clouds are observed from $500 \mathrm{~m}$ to $3.5 \mathrm{~km}$ altitude, which is the same range as is seen for thermal inversion layer depths (Lesins et al., 2009b). This correlation suggests that mixed-phase clouds are connected to the development of wintertime thermal inversion layers. Radiative transfer will be very sensitive to the vertical distribution of water clouds, and these new data should be taken into account in any future models of Arctic climate.

A classification chart was produced which allows for the identification of ice crystals, aerosols and water droplets from a combination of depolarization and colour ratio values. The chart allows a deeper understanding of the particles found above Eureka's by associating them with a shape and size-related parameter.

Future efforts are needed to improve our understanding of particle microphysics and optical properties. In-situ measurements of particle morphologies are required to understand the relationship between size, shape and depolarization. This may be partly possible from ground level since each ice crystal type is observed to precipitate to the surface, and no comprehensive study of this kind in the Arctic currently exists. However, there is also need for a wintertime aircraft campaign for ice particle sampling to resolve some of the depolarization and particle size issues identified here. Such a campaign should be performed in tandem with comparisons between different remote sensing techniques in order to form a comprehensive picture of particulates in the Arctic troposphere.

Acknowledgements. Financial support for this research was provided by the Canadian Foundation for Climate and Atmospheric Research (CFCAS), the Canadian Foundation for Innovation (CFI), the National Science and Engineering Research Council (NSERC) of Canada, the Canadian Space Agency (CSA), the Ontario Innovation Trust (OIT), the Ontario Research Fund (ORF), the Nova Scotia Research and Innovation Trust (NSRIT), the Government of Canada International Polar Year fund, and NSF grant ARC-0612452 and NOAA contract RA133R07CN0281. Logistical and other in-kind support from Environment Canada, the staff of the Eureka Weather Station, the PEARL Manager Pierre Fogal and Operators Alexei Khmel, Paul Loewen, Oleg Mikhailov, Ashley Harrett and Matthew Okraszewski is gratefully acknowledged.

Edited by: T. Garrett 


\section{References}

Blanchet, J.-P. and Girard, E.: Water vapor-temperature feedback in the formation of continental Arctic air: its implication for climate, Sci. Total Environ., 160/262, 793-802, 1995.

Brown, P. R. A. and Francis, P. N.: Improved measurements of the ice water content in cirrus using a total-water probe, J. Atmos. and Ocea. Tech., 12, 410-414, 1995.

Curry, J.: On the formation of continental polar air, J. Geophys. Res., 40, 2278-2292, 1983.

Curry, J. A., Schramm, J. L., and Ebert, E. E.: Impact of clouds on the surface radiation balance of the Arctic Ocean, Meteorol. Atmos. Phys., 51, 197-217, 1993.

Curry, J. A., Rossow, W. B., Randall, D., and Schramm, J. L.: Overview of Arctic cloud and radiation characteristics, J. Climate, 9, 1731-1764, 1996.

Curry, J. A., Hobbs, P. V., King, M. D., Randall, D. A., Minnis, P., Isaac, G. A., Pinto, J. O., Uttal, T., Bucholtz, A., Cripe, D. G., Gerber, H., Fairall, C. W., Garrett, T. J., Hudson, J., Intrieri, J. M., Jakob, C., Jensen, T., Lawson, P., Marcotte, D., Nguyen, L., Pilewskie, P., Rangno, A., Rogers, D. C., Strawbridge, K. B., Valero, F. P. J., Williams, A. G., and Wylie, D.: FIRE Arctic Clouds Experiment, B. Am. Meteor. Soc., 81, 5-29, 2000.

Donovan, D. P. and van Lammeren, A. C. A. P.: Cloud effective particle size and water content profile retrievals using combined lidar and radar observations 1 . Theory and examples, J. Geophys. Res., 106, 27425-27448, 2001.

Donovan, D. P., and van Lammeren, A. C. A. P.: First ice cloud effective particle size parameterization based on combined lidar and radar data, Geophys. Res. Lett., 29(1), 1006, doi:10.1029/2001GL013731, 2002.

Grenier, P., Blanchet, J.-P., and Muñoz-Alpizar, R.: Study of polar thin ice clouds and aerosols seen by CLOUDSAT and CALIPSO during mid-winter 2007, J. Geophys. Res., 114, D09201, doi:10.1029/2008JD010927, 2009.

Grenfell, T. C. and Warren, S. G.: Representation of a nonspherical ice particle by a collection of independent spheres for scattering and absorption of radiation, J. Geophys. Res., 104, 3169731709, 1999.

Grenfell, T. C., Neshyba, S. P., and Warren, S. G.: Representation of a nonspherical ice particle by a collection of independent spheres for scattering and absorption of radiation: 3 . Hollow columns and plates, J. Geophys. Res., 110, D17203, doi:10.1029/2005JD005811, 2005.

Hoff, R. M.: Vertical structure of Arctic haze observed by lidar, J. Appl. Meteor., 27, 125-139, 1988.

Intrieri, J. M. and Shupe, M. D.: Characteristics and radiative effects of diamond dust over the Western Arctic Ocean region, J. Climate, 17, 2953-2960, 2004.

Korolev, A. V., Isaac, G. A., and Hallett, J.: Ice particle habits in Arctic clouds, Geophys. Res. Lett., 9, 1299-1302, 1999.

Lesins, G., Bourdages, L., Duck, T. J., Drummond, J. R., Eloranta, E. W., and Walden, V. P.: Large surface radiative forcing from topographic blowing snow residuals measured in the High Arctic at Eureka, Atmos. Chem. Phys., 9, 1847-1862, 2009, http://www.atmos-chem-phys.net/9/1847/2009/.

Lesins, G., Duck, T. J., and Drummond, J. R.: Climatology of Eureka in the Canadian High Arctic, Atmos.-Ocean., submitted, 2009.

Lawson, R. P., Baker, B. A., and Schmitt, C. G.: An overview of mi- crophysical properties of Arctic clouds observed in May and July 1998 during FIRE ACE, J. Geophys. Res., 106, 14989-15014, 2001.

Leaitch, W. R., Hoff, R. M., and MacPherson, J. I.: Airborne and lidar measurements of aerosol and cloud particles in the troposphere over Alert Canada in April 1986, J. Atmos. Chem, 9, 187211, 1989.

Mahesh, A., Walden, V. P., and Warren, S. G.: Ground-based infrared remote sensing of cloud properties over the Antarctic Plateau. Part II: Cloud optical depths and particle sizes, J. Appl. Meteorol., 40, 1279-1294, 2001.

Matrosov, S. Y., Korolev, A. V., and Heymsfield, A. J.: Profiling cloud mass and particle characteristic size from Doppler radar measurements, J. Atmos. and Ocea. Tech., 19, 1003-1018, 2002.

Moran, K., Martner, B., Post, M., Kropfli, R., Welsh, D., and Widener, K.: An unattended cloud-profiling radar for use in climate research, B. Am. Meteor. Soc., 79, 443-355, 1998.

Mishchenko, M. L., Travis, L. D., and Lacis, A. A.: Scattering, absorption, and emission of light by small particles, Cambridge University Press, ISBN 0-521-78252-X, 448 pp., 2002.

Neshyba, S. P., Grenfell, T. C., and Warren, S. G.: Representation of a nonspherical ice particle by a collection of independent spheres for scattering and absorption of radiation: 2. Hexagonal columns and plates, J. Geophys. Res, 108(D15), 4448, doi:10.1029/2002JD003302, 2003.

Nishimura, K. and Nemoto, M.: Blowing snow at Mizuho station, Antarctica, Phil. Trans. R. Soc. A, 363, 1647-1662, doi:10.1098/rsta.2005.1599, 2005.

Razenkov, I., Eloranta, E., Hedrick, J., Holz, R., Kuehn, R., and Garcia, J.: A high spectral resolution lidar designed for unattended operation in the Arctic, in: Lidar Remote Sensing in Atmospheric and Earth Sciences, edited by: Bissonnette, L. R., Roy, G., and Vallee, G., 57-60, Defence R\&D Canada-Valcartier, Val-Belair, Quebec, Canada, 2002.

Sassen, K.: Contrail-cirrus and their potential for regional climate change, B. Am. Meteor. Soc., 78, 1885-1903, 1997.

Serreze, M. C., Barrett, A. P., Stroeve, J. C., Kindig, D. N., and Holland, M. M.: The emergence of surface-based Arctic amplification, The Cryosphere, 3, 11-19, 2009, http://www.the-cryosphere-discuss.net/3/11/2009/.

Shupe, M. D., Kollias, P., Persson, P. O. G., and McFarquhar, G. M.: Vertical motions in Arctic mixed-phase stratiform clouds, J. Atmos. Sci., 65(4), 1304-1322, doi:10.1175/2007JAS2479.1, 2008.

Trivett, N. B. A., Barrie, L. A., Bottenheim, J. W., Blanchet, J.-P., den Hartog, G., Hoff, R. M., and Mickle, R. E.: An experimental investigation of Arctic haze at Alert, N. W. T., March 1985, Atmos. Ocean., 26, 341-376, 1988.

Turner, D. D.: Arctic mixed-phase cloud properties from AERI lidar observations: Algorithm and results from SHEBA, J. Appl. Meteorol., 44, 427-444, 2005.

Uttal, T., Curry, J. A., McPhee, M. G., Perovich, D. K., Moritz, R. E., Maslanik, J. A., Guest, P. S., Stern, H. L., Moore, J. A., Turenne, R., Heiberg, A., Serreze, M. C., Wylie, D. P., Persson, O. G., Paulson, C. A., Halle, C., Morison, J. H., Wheeler, P. A., Makshtas, A., Welch, H., Shupe, M. D., Intrieri, J. M., Stamnes, K., Lindsey, R. W., Pinkel, R., Pegau, W. S., Stanton, T. P., and Grenfeld, T. C.: Surface Heat Budget of the Arctic Ocean, B. Am. Meteor. Soc., 83, 255-275, 2002. 
Verlinde, J., Harrington, J. Y., McFarquhar, G. M., Yannuzzi, V. T., Avramov, A., Greenberg, S., Johnson, N., Zhang, G., Poellot, M. R., Mather, J. H., Turner, D. D., Eloranta, E. W., Zak, B. D., Prenni, A. J., Daniel, J. S., Kok, G. L., Tobin, D. C., Holz, R., Sassen, K., Spangenberg, D., Minnis, P., Tooman, T. P., Ivey, M. D., Richardson, S. J., Bahrmann, C. P., Shupe, M., DeMott, P. J., Heymsfield, A. J., and Schofield, R.: The Mixed-Phase Arctic Cloud Experiment, B. Am. Meteor. Soc., 80, 205-221, 2007.

Walden, V. P., Warren, S. G. and Tuttle, E.: Atmospheric ice crystals over the Antarctic Plateau in winter, J. Appl. Meteorol., 42, 1391-1405, 2003.

Wang, Z. and Sassen, K.: Cirrus cloud microphysical property retrieval using lidar and radar measurements. Part I: Algorithm description and comparison with in situ data, J. Appl. Meteorol., 41, 218-229, 2002.
Warren, S. G., and Brandt, R. E.: Optical constants of ice from the ultraviolet to the microwave: A revised compilation, J. Geophys. Res., 113, D14220, doi:10.1029/2007JD009744, 2008.

Wexler, H.: Cooling in the lower atmosphere and the structure of polar continental air, Mon. Weather Rev., 64, 122-136, 1936.

Whiteway, J. A., Cook, C., Gallagher, M., Choularton, T., Harries, J., Connolly, P., Busen, R., Bower, K., Flynn, M., May, P., Aspey, R., and Hacker, J.: Anatomy of cirrus clouds: Results from the Emerald airborne campaigns, Geophys. Res. Lett., 31, L24102, doi:10.1029/2004GL021201, 2004.

Zhao, C. and Garrett, T. J.: Ground-based remote sensing of precipitation in the Arctic, J. Geophys. Res., 113, D14204, doi:10.1029/2007JD009222, 2008. 